\title{
Preventing foot complications in diabetes - The St Vincent Declaration 25 years on
}

\author{
MARIE-FRANCE KONG, ROBERT GREGORY
}

\section{Introduction}

In 1989 representatives of government health departments and patients' organisations from all European countries met diabetes experts in the Italian village of St Vincent and agreed a number of recommendations for member states to adhere to in order to improve diabetes care for their citizens. The target set for feet was to "reduce the numbers of limb amputations for diabetic gangrene by $50 \%$ in a five year period ". "The ambitious targets were intended to kick-start governments and healthcare services into action. Equity of access and strong partnerships in care for people with diabetes was another target. It speaks volumes about the failure to meet the St Vincent target that this journal carries an article announcing the second campaign in two years on the subject of diabetic foot care.

\section{Current situation}

Worldwide, diabetes-related complications result in the amputation of a lower limb every 30 seconds. ${ }^{2}$ Around 6,000 people with diabetes have leg, foot or toe amputations each year in England; this is over 100 amputations a week. ${ }^{3}$ There are 450 amputations a year in Scotland. ${ }^{4}$ Amputation rates are set to rise to more than 7,000 in 2014/15 in England. ${ }^{5}$ Data for the UK showing a tenfold variation in the incidence of major amputation in people with and without diabetes offers a way forward, exploiting the motivational technique of the 'league table'. ${ }^{6}$ While racial and demographic factors account for some of the observed variation, much of it reflects differences in clinical practice, for example differences in the availability and organisation of specialist services (multidisciplinary foot teams) and differences in speed of referral.

About half of lower limb amputations are in people with diabetes. ${ }^{5}$ There is a pressing need to raise awareness of foot complications to reduce the number of amputations in people with diabetes. The lifetime risk for any diabetic patient for developing a foot ulcer is up to $15 \% .^{7}$ More than half of all foot ulcers will become infected, requiring hospitalization, and $20 \%$ of infections re-

Department of Diabetes, University Hospitals of Leicester NHS Trust, Leicester General Hospital, Leicester, UK

Address for correspondence: Marie-France Kong Department of Diabetes, University Hospitals of Leicester NHS Trust, Leicester General Hospital, Gwendolen Road, Leicester, LE5 4PW, UK Tel: +44 (0)116 2588304 Fax: +44 (0)116 2733067

E-mail: marie-france.kong@uhl-tr.nhs.uk

Br J Diabetes Vasc Dis 2014;14:43-44

http://dx.doi.org/10.15277/bjdvd.2014.017

\author{
Abbreviations and acronyms \\ CCG \\ MDT \\ clinical commissioning group \\ multidisciplinary team \\ National Health Service
}

sult in amputation. ${ }^{8}$ Diabetic foot ulcers double mortality and heart attack risk and there is an increased risk for stroke of $40 \% .{ }^{9}$ The 5 year survival for people with diabetes following a new foot ulcer is between $40 \%$ and $50 \%$, worse than many cancers. Diabetic foot disease cost $\mathrm{f} 600$ million in $2010-11$ - approximately $0.6 \%$ of the total NHS healthcare budget for England.

Foot examination focusing on the presence of peripheral neuropathy, peripheral artery disease and abnormal foot anatomy can predict patients at high risk of developing foot ulcers. ${ }^{10}$ Unfortunately, $15 \%$ of patients with diabetes are still not getting their annual foot check and there is variation between regions. In 2009/10 less than a third had their feet examined at any time during an admission to hospital and $2.2 \%$ developed a new foot ulcer whilst an inpatient. ${ }^{11}$ Over a quarter (26.8\%) of hospitals have no inpatient podiatry service.

There is a pressing need for raising patient awareness and empowering them to look after their feet. We need to improve education and training for staff working in primary care and to ensure that all healthcare professionals looking after people with diabetes know how to carry out foot checks and act according to the results.

A footcare pathway should be available to facilitate best practice. Recently it has been shown that CCGs without a patient pathway for peripheral arterial disease had $11 \%$ more amputations on average than those with a pathway. A further factor for high amputation rates is the absence of MDTs. Almost a third of acute trusts lacked MDTs for vascular and diabetes patients and 28\% lacked MDTs for peripheral arterial disease.

\section{Recommendations}

Standards of care should be monitored nationally, and the impact on amputation rates should be measured. All staff should participate in audits, and we would encourage those working in England and Wales to register with the first National Diabetes Footcare Audit due to be launched in July 2014. This, together with the "Foot Attack" and "Save Lives and Limbs" campaigns, offer hope for our patients.

\section{References}

1. WHO/IDF Saint Vincent Declaration Working Group. Diabetes Mellitus in Europe: a Problem at all Ages in all Countries. A Model for Prevention 
and Self Care. Acta Diabetol 1990;27:181-3.

2. Apelqvist J, Agardh CD. The association between clinical risk factors and outcome of diabetic foot ulcers. Diabetes Res Clin Pract 1992;18:43-53. http://dx.doi.org/10.1016/0168-8227(92)90054-U

3. The Health and Social Care Information Centre Hospital Episode Statistics 2007/8 - 2010/11 and based on the number of inpatient episodes where amputations occurred in the period (2007- 2010) and there was a diagnosis of diabetes. Source: Diabetes Footcare Activity Profiles http://www.yhpho.org.uk/default.aspx?RID $=116836$ (Accessed May 2014)

4. NHS Scotland (2010). Scottish Diabetes Survey 2010 - http://www. diabetesinscotland.org.uk/Publications/SDS\%202010.pdf (Accessed May 2014)

5. The Information Centre for Health and Social Care. Hospital Episode Statistics 2007/08-2010/11 via http://www.hscic.gov.uk/ (Accessed May 2014)

6. Holman N, Young RJ, Jeffcoate WJ. Variation in the recorded incidence of amputation of the lower limb in England. Diabetologia 2012; 55:1919-25. http://dx. doi.org/10.1007/s00125-012-2468-6
7. Reiber GE, Lipsky BA, Gibbons GW. The burden of diabetic foot ulcers. Am J Surg 1998;176:5S-10S.

http://dx.doi.org/10.1016/S0002-9610(98)00181-0

8. Lavery LA, Armstrong DG, Wunderlich RP, Mohler MJ, Wendel CS, Lipsky BA. Risk factors for foot infections in individuals with diabetes. Diabetes Care 2006;29:1288-93. http://dx.doi.org/10.2337/dc05-2425

9. Brownrigg JR, Davey J, Holt PJ et al. The association of ulceration of the foot with cardiovascular and all-cause mortality in patients with diabetes: a meta-analysis. Diabetologia 2012;55:2906-12.

http://dx.doi.org/10.1007/s00125-012-2673-3

10. Abbott CA, Carrington AL, Ashe $\mathrm{H}$ et al. The North-West Diabetes Foot Care Study: incidence of, and risk factors for, new diabetic foot ulceration in a community-based patient cohort. Diabet Med 2002;19:377384. http://dx.doi.org/10.1046/j.1464-5491.2002.00698.x

11. National diabetes inpatient audit 2010 full report - YHPHO www.yhpho.org.uk/resource/view.aspx?RID=106455 (Accessed May 2014)

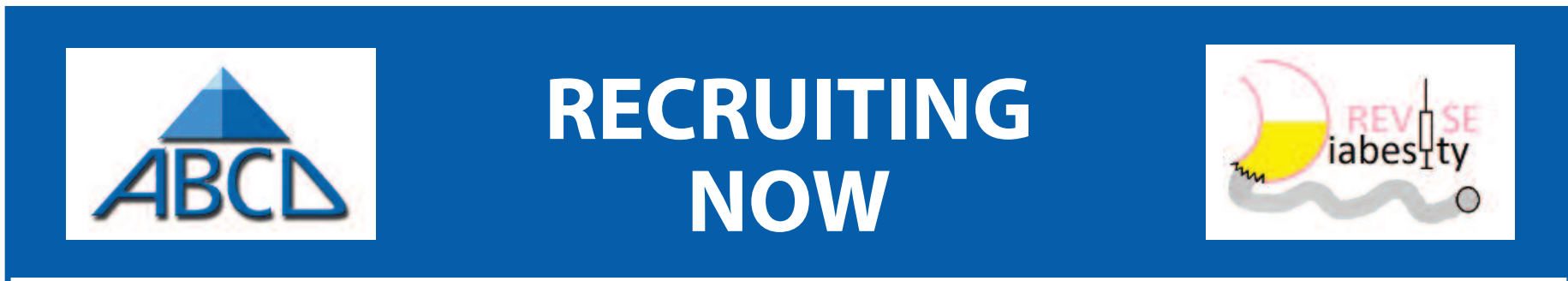

\title{
Do you have patients with type 2 diabetes and obesity needing better control, despite previous liraglutide use?
}

REVISE-Diabesity is a randomised controlled trial which offers the real chance of improved glycaemic control and reduced weight to enrolled participants, who will be randomised to: 1) Liraglutide 1.8mg, 2) Endobarrier, 3) Endobarrier + liraglutide Endobarrier is an endosopically inserted duodenal-jejunal bypass liner which early studies suggest might lead to considerable weight loss and improved glycaemic control

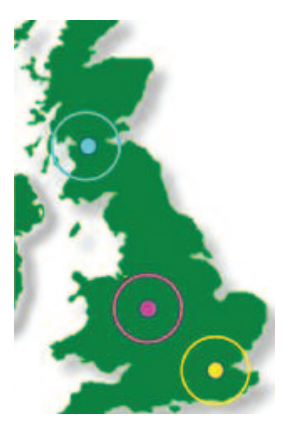

\author{
To refer patients (Glasgow/ Birmingham / London) \\ please contact: \\ Dr Piya Sen Gupta, \\ ABCD Research Fellow \\ Email: revise.diabesity@nhs.net \\ Mobile: 07866319487
}

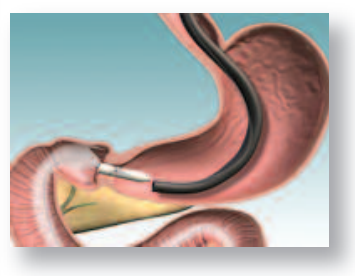

Please see the study website (includes selection criteria):

http://www.diabetologists-abcd.org.uk/research/endobarrier_study.htm

ISRCTN00151053, NCT02055014 